\title{
Neighbourhood level and individual level SES effects on child problem behaviour: a multilevel analysis
}

A C Kalff, M Kroes, J S H Vles, J G M Hendriksen, F J M Feron, J Steyaert, T M C B van Zeben, J Jolles, J van Os

\section{Department of Psychiatry and Neuropsychology, Maastricht University, the Netherlands A C Kalff \\ J Steyaert \\ J Jolles}

Department of Neurology, Academic Hospital of Maastricht, the Netherlands M Kroes

J S H Vles

Child Revalidation Centre

Franciscusoord, Valkenburg, the Netherlands J G M Hendriksen

Youth Health Care of the Municipal Health Centre, Maastricht, the Netherlands F J M Feron

Paediatric

Department, Academic Hospital of Maastricht, the Netherlands

T M C B van Zeben

Department of Psychiatry and Neuropsychology, Maastricht University, the Netherlands and Institute of Psychiatry, London, United Kingdom

$\mathrm{J}$ van Os

Correspondence to: Professor van Os, Department of Psychiatry and Neuropsychology, Section Social Psychiatry and Psychiatric Epidemiology, Maastricht University, European Graduate School of Neuroscience, PO Box 616, $6200 \mathrm{MD}$ Maastricht, the Netherlands

(j.vanos@sp.unimaas.nl)

Accepted for publication 5 October 2000 neighbourhood level socioeconomic variables have an independent effect on reported child behaviour problems over and above the effect of individual level measures of socioeconomic status.

Design and setting-Multilevel analysis of cross sectional survey data relating individual level child behavioural problems and parental measures of socioeconomic status with neighbourhood level measures of socioeconomic deprivation in the city of Maastricht, the Netherlands.

Participants-Children born in the years 1990-1991 attending the second grade of normal kindergarten schools in the city of 5-7 year olds, the parents of 734 children $(51.8 \%)$ agreed to participate. Main results-Child behaviour problems were more frequent in families of low parental occupation and education $(F=14.51$, df 3, 721, p < 0.001; $F=12.20$, df 3, $721, p<0.001$, respectively) and in families living in deprived neighbourhoods $(F=13.26$, df $2,722, p<0.001)$. Multilevel random effects regression analysis showed that the effect of neighbourhood level deprivation remained after adjustment for individual level socioeconomic status (B over three levels of deprivation: 1.36; $95 \% \mathrm{CI}=0.28,2.45$ ).

Conclusions-Living in a more deprived neighbourhood is associated with higher levels of child problem behaviour, irrespective of individual level socioeconomic status. The additional effect of the neighbourhood may be attributable to contextual variables such as the level of social cohesion among residents. (F Epidemiol Community Health 2001;55:246-250)

As it is known that behaviour problems in children increase the risk for later psychopathology, ${ }^{1}$ unravelling the aetiology of early problem behaviour may provide possibilities for prevention of adult mental disorder. Many studies have shown that individual level variables, such as exposure to marital discord or coming from a low income family, are associated with behaviour problems in children. ${ }^{2-4}$ In addition, behaviour problems occur more frequently in children living in deprived urban areas than in children living in rural communities. ${ }^{5}{ }^{6}$ However, whether neighbourhood level socioeconomic variables have an independent effect on child behaviour problems over and above the effect of individual level variables has scarcely been studied. Duncan and colleagues have demonstrated that neighbourhood economic conditions and poverty status are powerful correlates of the behaviour of children even after accounting for family structure and maternal education. ${ }^{7}$ However, most studies on the effects of neighbourhood on child behaviour have been hampered by the absence of data combining information at the individual, family, and neighbourhood levels in the appropriate statistical model. ${ }^{8}$

Thus, most studies on neighbourhood differences on child behaviour problems have not taken into account the hierarchical fashion in which such data are organised. Data that are grouped according to neighbourhood are, in statistical terms, part of a multilevel structure, with level one units (individuals) being clustered into level two units (neighbourhoods). Individuals from the same neighbourhood are more similar to each other than individuals from different areas, implying that the variation of reported child behaviour problems is smaller than if it were completely random. A conventional regression technique cannot take into account the variance components of two different levels, thus underestimating the standard errors of regression coefficients. ${ }^{9}$ Therefore, multilevel techniques should be used with a two level hierarchical structure (individual and neighbourhood level).

Recently, several studies on adult mental health have used such multilevel techniques. There is now increasing interest in the question to what extent adult mental health outcomes are influenced by neighbourhood level socioeconomic variables, over and above the effect of their individual level counterparts. ${ }^{10-13}$ In line with these studies, the goal of this study is to examine the independent impact of ecological, neighbourhood level variables on the behaviour problems in children with multilevel analyses, to give further insight into the pathways of risk. For example, the socioeconomic status of deprived neighbourhoods, which is associated with a low level of neighbourhood social capita $^{14}$ and poor neighbourhood social cohesion, ${ }^{15}$ could contribute to the development of behaviour problems in addition to the role of the low socioeconomic status of the family. 
This may have implications for prevention programmes aiming to reduce the prevalence of behavioural problems in children.

This report is part of a larger study, the Study of Attention disorders in Maastricht (SAM), and involves a prospective cohort study of the precursors of Attention Deficit/ Hyperactivity Disorder (ADHD) (unpublished data). We used multilevel techniques ${ }^{17}$ to examine the distribution of parent reported behaviour problems in a large urban community sample of 5 to 7 year old children living in neighbourhoods of varying degrees of deprivation. We hypothesised that behaviour problems in children would be affected by contextual neighbourhood level effects over and above the effect of individual level socioeconomic variables.

\section{Methods}

SUBJECTS AND PROCEDURE

Two datasets were combined, namely, individual characteristics (children from the birth cohort 1990-1991 and their families) from the SAM study (unpublished data) and neighbourhood characteristics from the Maastricht Mental Health Case Register data base. ${ }^{10}$ Maastricht is a relatively small city (population 121000 ) located in the extreme south of the Netherlands, and is the capital of the province of Limburg. The population is of relative ethnic homogeneity, there being relatively few nonDutch inhabitants, in comparison with the ethnically more heterogeneous populations in the cities in the north west of the country. Only children living within the city limits were included in this study.

Children were recruited during the basic periodic systemic health examination performed by the Youth Health Care (YHC) in the province of Limburg. All children were in the second grade of normal kindergarten schools and their parents were asked to participate in accordance with the guidelines of the local ethics committee. Demographic information was obtained from the medical records of the YHC. Out of 2290 children in second kindergarten grade, the parents of 1317 children $(57.5 \%)$ agreed to participate in the SAM study; 973 parents $(42.5 \%)$ refused participation. For a sample of the non-responders $(n=200)$ demographic information was obtained anonymously from the medical records of the YHC to compare their characteristics with those of the responders. There were no large or significant differences in sex, age, parental education and occupation, marital state, country of birth or living areas. No data on behaviour problems were available for the non-responders.

As we included only children living in the city of Maastricht in this study, our final sample included 734 children, representing $51.8 \%$ of the total number of eligible children in the SAM study who were living in the city of Maastricht $(n=1417)$. The sample consisted of 388 boys and 346 girls; the mean age was 66.9 months (SD 4.5, range 57.7-83.0). Children were also excluded if they lived in very small neighbourhoods, or neighbourhoods consisting mainly of industrial estates $(n=7)$; or if one or more of the individual socioeconomic variables were missing $(n=41)$.

\section{DEPENDENT VARIABLES: CHILD BEHAVIOUR}

PROBLEMS

The parent reported behaviour problems of the children were assessed with the Child Behavior Checklist $(\mathrm{CBCL})^{18}$; Dutch version. ${ }^{19}$ This questionnaire consists of 120 items on behaviour and emotional problems on a 3 point Likert scale. The questionnaire yields $\mathrm{T}$ scores with a mean of 50 and a standard deviation of 10. A total problem score is computed by summing all the scores. A total problem score of $\mathrm{T}$ $>63$ is usually considered as clinically deviant behaviour. ${ }^{19}$ In this study, the continuous total problem score was used rather than the frequently used dichotomisation because the latter results in loss of information. ${ }^{13}$

In most cases, the mothers completed the CBCL (88.1\% mothers; $9.4 \%$ fathers; $1.6 \%$ both parents; $0.8 \%$ unknown). After adjustment for missing data, the CBCL total scores were found to be significantly higher when reported by the mothers than when reported by the fathers $(F(2,725)=3.13 ; \mathrm{p}=.04)$.

INDEPENDENT VARIABLES: INDIVIDUAL LEVEL The educational level and occupational status of the parents were used as indicators of individual level socioeconomic status. The highest level of the mother or father was used. Level of parental education was measured on an 8 point scale ranging from primary education to higher vocational training and university. ${ }^{20}$ It was divided a priori into three levels: low (1 and 2), middle (3, 4 and 5), and high (6, 7 and 8). Parental occupation was scored on a 7 point scale ranging from low skilled to scientific labour, ${ }^{21}$ also divided a priori into three levels: low (1 and 2), middle (3, 4 and 5), and high (6 and 7). Other independent variables were parental marital status (married, divorced, widowed, or lone parents who were neither married, divorced nor widowed) and country of birth of the parents (the Netherlands or another country). Of the 11 lone parents, four were living as a two parent family and were therefore added to the category "married". The remaining were living as a single parent family and were added to the "divorced" category. If either one or both of the parents were born in another country, this was registered as "foreign born".

\section{INDEPENDENT VARIABLES: NEIGHBOURHOOD}

LEVEL

In a previous study, the 36 different neighbourhoods in Maastricht had been classified using six neighbourhood level socioeconomic indicators obtained from the local authority: neighbourhood level of unemployment, dependence on social welfare, single parent families, non-voters, foreign born, and migrations (moving to and from Maastricht). ${ }^{10}$ The first principal component of these variables was divided 
by its tertiles and served as a three level indicator of neighbourhood socioeconomic deprivation (least, intermediate and most deprived neighbourhoods)..$^{10}$

STATISTICAL ANALYSES

All analyses were performed using STATA, version $6 .^{22}$ Firstly, the distribution of parent reported child behaviour problems was computed for the individual level socioeconomic variables and for the three neighbourhood levels of deprivation. One way analysis of variance was performed to examine the effect of these socioeconomic status variables on total problem behaviour, adjusted for sex, age, and reporter of the CBCL. Tukey multiple comparison procedure was used to analyse group differences. Then, the effect of neighbourhood level of deprivation on total problem behaviour was examined. To assess whether neighbourhood characteristics had an independent effect on total problem behaviour over and above the effect of individual socioeconomic factors, the measures of individual level socioeconomic variables were added to the multilevel model in

Table 1 Demographic characteristics of the sample by three neighbourhood levels (number and percentage (in parentheses))

\begin{tabular}{lcrrr}
\hline & Number & Least deprived & Intermediate & Most deprived \\
\hline $\begin{array}{l}\text { Total } \\
\text { Sex }\end{array}$ & $734(100.0)$ & $235(32.0)$ & $231(31.5)$ & $268(36.5)$ \\
boys & & & & \\
girls & $388(52.9)$ & $125(32.2)$ & $119(30.7)$ & $144(37.1)$ \\
$\begin{array}{l}\text { Marital state } \\
\text { married }\end{array}$ & $346(47.1)$ & $110(31.8)$ & $112(32.4)$ & $124(35.8)$ \\
divorced & $644(87.7)$ & $216(33.5)$ & $205(31.8)$ & $223(34.6)$ \\
widowed & $85(11.6)$ & $17(20.0)$ & $25(29.4)$ & $43(50.6)$ \\
Country of birth of parents & $5(0.7)$ & $2(40.0)$ & $1(20.0)$ & $2(40.0)$ \\
Netherlands & $642(87.5)$ & $219(34.1)$ & $204(31.8)$ & $219(34.1)$ \\
foreign born & $92(12.5)$ & $16(17.4)$ & $27(29.3)$ & $49(53.3)$ \\
$\begin{array}{l}\text { Parental education } \\
\text { high }\end{array}$ & $318(43.3)$ & $136(42.8)$ & $114(35.8)$ & $68(21.4)$ \\
middle & $224(30.5)$ & $72(32.1)$ & $66(29.5)$ & $86(38.4)$ \\
low & $126(17.2)$ & $14(11.1)$ & $42(33.3)$ & $70(55.6)$ \\
not known & $66(9.0)$ & $13(19.7)$ & $9(13.6)$ & $44(66.7)$ \\
$\begin{array}{l}\text { Parental occupation } \\
\text { high }\end{array}$ & & & & \\
middle & $227(30.9)$ & $112(49.3)$ & $66(29.1)$ & $49(21.6)$ \\
low & $198(27.0)$ & $70(35.4)$ & $78(39.4)$ & $50(25.3)$ \\
not known & $261(35.6)$ & $48(18.4)$ & $77(29.5)$ & $136(52.1)$ \\
& $48(6.5)$ & $5(10.4)$ & $10(20.8)$ & $33(68.8)$ \\
\hline
\end{tabular}

Table 2 Univariate analyses with individual level and neighbourhood level socioeconomic variables for the total problem scores on the CBCL adjusted for sex, age, and reporter of the $C B C L$

\begin{tabular}{|c|c|c|c|c|c|}
\hline & \multicolumn{2}{|c|}{$C B C L$ total t score } & \multirow[b]{2}{*}{$d f$} & \multirow[b]{2}{*}{$F$} & \multirow{2}{*}{$\begin{array}{l}\text { Post hoc } \\
\text { pairwise } \\
\text { comparison }\end{array}$} \\
\hline & Mean & $S D$ & & & \\
\hline \multicolumn{6}{|l|}{ Marital state } \\
\hline married $(\mathrm{M})$ & 48.77 & 11.65 & 2,722 & $13.15^{\star \star \star}$ & $M<D$ \\
\hline divorced (D) & 55.65 & 13.46 & & & $\mathrm{~W}<\mathrm{D}$ \\
\hline widowed (W) & 42.00 & 4.84 & & & \\
\hline \multicolumn{6}{|c|}{ Country of birth of parents } \\
\hline Netherlands & 49.25 & 11.82 & 732 & -1.66 & NSt \\
\hline foreign born & 51.47 & 13.48 & & & \\
\hline \multicolumn{3}{|l|}{ Parental education } & 3,721 & $12.20^{\star \star \star}$ & $\mathrm{H}<\mathrm{M}, \mathrm{L}$ \\
\hline high $(\mathrm{H})$ & 46.79 & 11.60 & & & $\mathrm{M}<\mathrm{L}$ \\
\hline middle $(\mathrm{M})$ & 50.54 & 11.04 & & & \\
\hline low (L) & 53.92 & 11.90 & & & \\
\hline unknown (U) & 50.88 & 14.56 & & & \\
\hline \multicolumn{3}{|l|}{ Parental occupation } & 3,721 & $14.51^{\star \star \star}$ & $\mathrm{H}<\mathrm{L}, \mathrm{U}$ \\
\hline $\operatorname{high}(\mathrm{H})$ & 46.02 & 11.28 & & & $\mathrm{M}<\mathrm{L}, \mathrm{U}$ \\
\hline middle $(M)$ & 48.73 & 11.47 & & & \\
\hline low (L) & 52.27 & 11.87 & & & \\
\hline not known (U) & 54.44 & 13.95 & & & \\
\hline \multicolumn{3}{|l|}{ Level of deprivation } & 2,722 & $13.26^{\star \star \star}$ & $\mathrm{L}<\mathrm{I}, \mathrm{M}$ \\
\hline least $(\mathrm{L})$ & 46.38 & 12.06 & & & \\
\hline intermediate (I) & 50.30 & 11.87 & & & \\
\hline $\operatorname{most}(\mathrm{M})$ & 51.61 & 11.68 & & & \\
\hline
\end{tabular}

KEY POINTS

- Behaviour problems in children were more frequent in families living in deprived neighbourhoods irrespective of individual level socioeconomic status.

- Neighbourhood effects may be mediated by contextual influences such as poor social cohesion.

- Intervention programmes for high risk children should not only focus on individual level characteristics but also on neighbourhood level characteristics.

addition to neighbourhood level of deprivation. The regression coefficients reflect the adjusted correlations between child behaviour problems and neighbourhood level of deprivation. Differences between the neighbourhoods on individual level socioeconomic and demographic variables were analysed using the $\chi^{2}$ test. The total problem score of the CBCL was analysed as a continuous dependent variable.

\section{Results}

DEMOGRAPHIC CHARACTERISTICS

Of the total sample, 235 children (32.0\%) lived in least deprived neighbourhoods, 231 children $(31.5 \%)$ in intermediate neighbourhoods, and 268 children $(36.5 \%)$ in most deprived neighbourhoods (table 1). There were no differences between the neighbourhoods in sex. Most parents were married $(87.7 \%)$. There were significant differences between the neighbourhoods in marital state $\left(\chi^{2}=10.01, \mathrm{p}=0.04\right)$. Of the divorced parents, $50.6 \%$ lived in the more deprived neighbourhoods. Most parents were born in the Netherlands (87.5\%). The country of birth of the parents differed significantly between the neighbourhoods $\left(\chi^{2}=15.26\right.$, $\mathrm{p}=0.00$ ), foreign born parents living more often in deprived neighbourhoods than parents born in the Netherlands.

Of the parents with a high level of education, $42.8 \%$ lived in the least deprived neighbourhoods. In contrast, $55.6 \%$ of the parents with a low level of education lived in the most deprived neighbourhoods. With regard to occupational level, $49.3 \%$ of the parents with the highest occupational level lived in the least deprived neighbourhoods, and $52.1 \%$ of the parents with lowest occupational level lived in the most deprived neighbourhoods. The level of parental education and occupation differed significantly between the neighbourhoods $\left(\chi^{2}=\right.$ 89.94, $\mathrm{p}=0.00, \chi^{2}=102.28, \mathrm{p}=0.00$, respectively).

CHILD BEHAVIOUR PROBLEMS AND UNIVARIATE ANALYSES

Individual level and neighbourhood level socioeconomic variables were significantly associated with the total problem score of the CBCL after adjustment for sex, age, and reporter of the CBCL (table 2). Living in a divorced family was significantly associated with parent reported problem behaviour in children. There were no differences in reported problem behaviour between children of parents born in 
Table 3 Multilevel random regression analyses with individual (level 1) and neighbourhood (level 2) socioeconomic status for the total problem scores on the CBCL

\begin{tabular}{|c|c|c|c|}
\hline & $\begin{array}{l}\text { Without adjustment } \\
B(95 \% \mathrm{CI})\end{array}$ & $\begin{array}{l}\text { Adjusted for } \\
\text { sex/age/reporter } \\
C B C L \\
B(95 \% C I)\end{array}$ & $\begin{array}{l}\text { Adjusted for sex/age/reporter } \\
C B C L / \text { marital state/country } \\
\text { of birth of parents/parental } \\
\text { education and occupation } \\
B(95 \% \text { CI) }\end{array}$ \\
\hline \multicolumn{4}{|c|}{ Neighbourhood socioeconomic status } \\
\hline least deprived & $0 \dagger$ & $0 \dagger$ & $0 \dagger$ \\
\hline intermediate & $3.92(1.77,6.07)^{\star \star \star}$ & $3.92(1.78,6.06)^{\star \star \star}$ & $2.64(0.52,4.75)^{\star}$ \\
\hline most deprived & $5.23(3.16,7.31)^{\star \star \star}$ & $5.38(3.30,7.45)^{\star \star \star}$ & $2.74(0.58,4.91)^{\star}$ \\
\hline \multicolumn{4}{|l|}{ Summary } \\
\hline Linear trend & $2.59(1.55,3.63)^{\star \star \star}$ & $2.67(1.63,3.71)^{\star \star \star}$ & $1.36(0.28,2.45)^{\star}$ \\
\hline
\end{tabular}

$\mathrm{CBCL}=$ Child Behavior Checklist $\mathrm{B}=$ regression coefficient; $95 \% \mathrm{CI}=95 \%$ confidence intervals. †Baseline; ${ }^{\star \star \star} \mathrm{p}<0.001 ;{ }^{\star} \mathrm{p}<0.05$.

the Netherlands and children of parents born elsewhere. Children with parents with a lower level of education and lower level of occupation scored significantly higher on the total problem score than children with parents with a higher level of education and occupation. Also, children living in the most and intermediate deprived neighbourhoods had significantly more reported behaviour problems than children living in the least deprived neighbourhoods.

MULTILEVEL ANALYSES

The aggregated measure of neighbourhood deprivation could be a reflection of some individual level variables, such as sex, age, or parental occupation. To examine whether the neighbourhood characteristics had an independent effect on children's behaviour problems over and above the individual SES factors, multilevel random effects regression analyses were conducted (table 3 ). The coefficients in table 3 reflect the adjusted effects of these ecological variables of interest.

The results showed that problem behaviour in children was associated with neighbourhood socioeconomic variables (summary linear trend $p<0.001$; table 3). Children living in the intermediate and most deprived neighbourhoods had significantly more behaviour problems than children living in the least deprived neighbourhoods. After adjustment for sex, age, and reporter of the problem behaviour, a significant neighbourhood effect remained (summary linear trend $\mathrm{p}<0.001$ ). This effect was attenuated when all individual level socioeconomic variables (sex, age, reporter of the CBCL, marital status, country of birth, parental education and occupation) were added to the multilevel model but remained statistically significant (summary linear trend $\mathrm{p}=0.014$ ).

\section{Discussion}

The most important finding of this study is that neighbourhood level socioeconomic variables have an independent effect on reported child behaviour problems, over and above the effect of individual level socioeconomic variables. The prevalence of child behaviour problems was higher in families living in deprived neighbourhoods, but this finding could only be partly explained by the individual level socioeconomic measures that are known to be highly correlated with level of neighbourhood deprivation. Thus, children of parents with a low level of education and occupation or children of single parent families have a higher risk of having behaviour problems when they live in a deprived neighbourhood than when they live in more affluent neighbourhoods.

Our results are in line with those of some other multilevel studies of individual and neighbourhood differences in adult mental health. Shouls et al, for example, demonstrated that contextual factors associated with deprived neighbourhoods have an effect on reported illness over and above the effect of individual level socioeconomic status. ${ }^{12}$ Also, van Os et al showed that neighbourhood variables, even after adjustment for their individual level counterparts, contributed to the onset of psychotic symptoms. ${ }^{13}$ In contrast, Reijneveld and Schene did not find an additional contextual effect on mental disorders over and above the effect of individual level factors. ${ }^{11}$ In this last study, mental disorders were assessed by means of a questionnaire and subsequently dichotomised according to a widely used, but arbitrary, cut off point. Their results thus possibly remained inconclusive because of loss of information associated with dichotomisation of the dependent variable. ${ }^{13}$

This study suggests that child behaviour problems cannot be explained entirely by individual factors such as low parental education or living in a single parent family, and that neighbourhood factors are also important. This leads to speculation about the nature of neighbourhood level risk factors. Rutter has demonstrated that factors such as the design of housing estates, personal overcrowding, and migrations (moving to and from a city) that give rise to fewer neighbourhood support networks, are associated with a child's behavioural outcome. ${ }^{6}$ Also, aspects of the shared family environment influence comorbid behaviour problems in children. ${ }^{23}$ However, characteristics of the individuals living in the neighbourhoods can still bring about these risks. The findings of ecological studies that controlled for individual level variables suggest that the effect of neighbourhood deprivation may be explained as an effect of what is commonly referred to as social capital and social cohesion. ${ }^{14}{ }^{1524}$ For example, Kawachi et al demonstrated that self rated poor health was associated with living areas with low levels of social capital, characterised by lack of social trust between citizens and few norms of reciprocity, even after adjustment for the individual level factors. In addition, Sampson et al showed that social cohesion among neighbours and collective efforts to maintain control are important factors in explaining variations in crime rates, irrespective of the socioeconomic status of the individuals. The studies suggest that the shared social environment, which is not attributable to individual level factors, may be an important contributor to risk for later social and psychopathological outcomes. Although the term social capital is often used in this context, its precise meaning is not clear, and there are many neighbourhood factors that can affect child behaviour. For example, differences in child rearing practices, 
provision of pre-school educational facilities, access to family advice and support, perception of risk of danger leading to children being protected differentially, could all exist at neighbourhood level and affect child behaviour. Future studies can additionally include these variables to assess their effects. However, the fact that in this study effects were found for a measure with high loadings on, for example, single parent families and proportion of foreign born does suggest that level of social isolation and social cohesion may be involved.

Three points of consideration emerge from the study. Firstly, not all individuals of the cohort participated, as is the case with most epidemiological studies. The response rate was low and this could have biased the findings. However, in order for such bias to explain the findings, one would have to assume that parents of children with few behaviour problems were differentially inclined towards non-response in deprived areas, but more likely to respond in non-deprived areas. While not impossible, this scenario is unlikely, and bias testing between responders and non-responders did not suggest systematic differences. Secondly, the data were limited to one city, a relatively small city in the Netherlands with a fairly ethnic homogeneous Dutch population. For this reason, our findings may not necessarily be valid for big cities with ethnically more mixed populations. Thirdly, we assessed the effect of neighbourhood deprivation at the individual level for three of the variables, namely, the proportion of single parent families, the level of parental occupation, and the number of foreign born parents. The other neighbourhood variables, such as nonvoters or migrations (moving to and from Maastricht), were not available at the individual level. Therefore, it is possible that, for example, individual level voting behaviour caused the additional neighbourhood effect. However, as single parent families and foreign born loaded highest on the neighbourhood deprivation score derived from the principal component analysis, ${ }^{10}$ we are confident that adjustment for these individual level variables would have caused the largest possible reduction in effect size.

In conclusion, irrespective of the socioeconomic status of the individual, parents report more behaviour problems in their children when they live in socially deprived neighbourhoods than when they live in more affluent neighbourhoods. Many studies have shown that children with behaviour problems at a young age are at risk for developing psychopathology later. ${ }^{1}$ Verhulst et al have emphasised the need for improved prevention and intervention measures in order to help children cope with the demands imposed by changing society. ${ }^{25}$ The fact that deprived neighbourhoods may pose an additional risk would imply that prevention programmes for high risk children should also focus on neighbourhood characteristics, in addition to the interventions already provided for high risk individuals. Further research is needed to determine the pathway of risk associated with the neighbourhood environment.

Funding: this study was financially supported by the Profilerings Fund of the Academic Hospital of Maastricht, the Netherlands, the Dutch Prevention Fund, and the Faculty of Medicine of Maasricht University, the Netherlands.

Conflicts of interest: none.

1 Campbell SB. Behavior problems in preschool children: a review of recent research. $\mathcal{F}$ Child Psychol Psychiatry 1995;36:113-49.

2 Lavigne JV, Gibbons RD, Kaufer Christoffel K, et al. Prevalence rates and correlates of psychiatric disorders among preschool children. If Am Acad Child Adolesc
Psychiatry1996;35:204-14.

3 Shaw DS, Winslow EB, Owens EB, et al. Young children's adjustment to chronic family adversity: A longitudinal adjustment to chronic family adversity: A longitudinal
study of low-income families. $\mathcal{F}$ Am Acad Child Adolesc Psystudy of low-income fam
chiatry 1998;37:545-53.

4 Verhulst FC, Akkerhuis GW, Althaus M. Mental health in Dutch children: (I) a cross-cultural comparison. Acta Psychiatr Scand 1985;232 (suppl 72):1-108.

5 Offord DR, Boyle MH, Szatmari P, et al. Ontario Child Health Study. II. Sex-month prevalence of disorder and rates of service utilization. Arch Gen Psychiatry 1987;44: $832-36$

6 Rutter M. The city and the child. Am f Orthopsychiatry 1981;51:610-25.

7 Duncan GJ, Brooks-Gunn J, Klebanov PK. Economic deprivation and early childhood development. Child Dev 1994; 65:296-318.

8 Brooks-Gunn J, Duncan GJ, Klebanov PK, et al. Do neighbourhoods influence child andadolescent development?

Am 7 Sociol 1993;99:353-93.
9 Hox J. Applied multilevel analyses. Amsterdam: TTPublikaties, 1995.

10 Driessen G, Gunther N, van Os J. Shared social environment and psychiatric disorder: a multilevel analysis of inidividual and ecological effects. Soc Psychiatry Psychiatr Epidemiol 1998:33:606-12.

11 Reijneveld SA, Schene AH. Higher prevalence of mental disorders in socioeconomically deprived urban areas in the Netherlands: community or personal disadvantage? $f$ Epidemiol Community Health 1998;52:2-7.

2 Shouls S, Congdon P, Curtis S. Modelling inequality in reported long term illness in the UK: combining individual and area characteristics. $\mathcal{F}$ Epidemiol Community Health 1996:50:366-76.

13 Van Os J, Driessen G, Gunther N, et al. Neighbourhood variation in schizophrenia incidence: Evidence for person-
environment interaction. Br f Psychiatry 2000;176:243-8.

14 Kawachi I, Kennedy BP, Glass R. Social capital and self-rated health: A contextual analysis. Am f Public Health 1999;89:1187-93.

15 Sampson RJ, Raudenbush SW, Earls F. Neighborhoods and Sampson RJ, Raudenbush SW, Earls F. Neighborhoods and
violent crime: A multilevel study of collective efficacy. Sciviolent crime: A multileve
ence 1997;277:918-24.

ence 1997;277:918-24.

17 Goldstein H. Multilevel models in educational and social Goldstein H. Multilevel models
research. London: Griffin, 1987.

18 Achenbach TM. Manual for the Child Behavior Checklist/ 4-18 and 1991 Profile. Burlington: University of Vermont Department of Psychiatry, 1991.

19 Verhulst FC, Koot JM, van der Ende J. Handleiding voor de CBCL (Child Behavior Checklist). [Manual for the CBCL]. Rotterdam: Afdeling Kinder- en Jeugdpsychiatrie, Sophia
Kinderziekenhuis/Academisch Ziekenhuis Rotterdam/ Erasmus Universiteit Rotterdam, 1996.

20 De Bie SE. Standaardvragen 1987: Voorstellen voor uniformering van vraagstellingen naar achtergrondkenmerken en interviews. [Standard questions 1987: Proposal for uniformization of questions regarding background variables and in of questions regarding background variables and

21 Van den Brand PA, Goldbohm RA, van't Veer P, et al. A large-scale prospective cohort study on diet and cancer in large-scale prospective cohort study on diet and canc
the Netherlands. $\mathcal{F}$ Clin Epidemiol 1990;43:285-95.

22 StataCorp. Stata statistical software: release 6. College Station, TX: Stata Corporation, 1999.

23 Gjone H, Stevenson J. The association between internalizing and externalizing behavior in childhood and early adolescence: genetic of environmental common influences? $\mathcal{f}$ Abnorm Child Psychol 1997;25:277-86.

24 Kawachi I, Kennedy BP. Health and social cohesion: why care about income inequality. BMF 1997;314:1037-40.

25 Verhulst FC, van der Ende J, Rietbergen A. Ten-year time trends of psychopathology in Dutch children and adolescents: no evidence for strong trends. Acta Psychiatr Scand 1997;96:7-13. 